\title{
Methicillin-Sensitive Staphylococcus aureus as a Cause of Lemierre's Syndrome
}

\author{
Carmen Pérez-Ortiz, Natalia Moya-Notario, Luciano Santana-Cabrera, \\ Beatriz del Amo-Nolasco, Manuel Sánchez-Palacios \\ Intensive Care Unit, Universitary Hospital Insular in Gran Canaria, Las Palmas de Gran Canaria, Spain \\ Email: Isancabx@gobiernodecanarias.org
}

Received 9 April 2014; revised 13 May 2014; accepted 24 May 2014

Copyright (C) 2014 by authors and OALib.

This work is licensed under the Creative Commons Attribution International License (CC BY).

http://creativecommons.org/licenses/by/4.0/

(c) (i) Open Access

\begin{abstract}
The Lemierre's syndrome (coexistence of oropharingeal infection, septic thrombophlebitis of the internal jugular vein and septic embolisms), rarely can be caused by Staphylococcus methicillin sensitive, showing a great virulence because of their capacity to produce a toxin called "PantonValentine Leukocidin". We present the case of a patient who was admitted to our ICU with a clinical picture of septic shock secondary to this syndrome, in which this pathogen was found as the etiologic agent.
\end{abstract}

\section{Keywords}

Lemierre's Syndrome, Panton-Valentine Leukocidin, Staphylococcus aureus

\section{Introduction}

Lemierre's syndrome is known as the triad of oropharyngeal infection, septic thrombophlebitis of the internal jugular vein and septic embolisms [1]. The etiologic agent is, in the majority of cases, the Prevotella necrophorum, although other germs such as Peptostreptococcus, Streptococcus and Porphyromonas have been also implicated [2]. Cases produced by Staphylococcus are less frequent and they are mostly caused by methicillin resistants bacteria, though some cases caused by sensitive strains have been also described showing great virulence [3]. According to some authors, this ability is related to the production of a toxin called "Panton-Valentine Leukocidin", causing inflammatory lesions, capillary dilation, local chemotaxis and infiltration by polymerphonuclear cells and necrosis of the skin [4] [5].

We present the case of a patient who presented a septic shock secondary to Lemierre's syndrome caused by methicillin-sensitive staphylococcus producers of Panton-Valentine leukocidin and acquired in the community. 


\section{Case Report}

Woman of 59 years without relevant pathological history presents bursitis in his left shoulder of a week of evolution treated with local injections of corticoids. Three weeks earlier she had suffered a catarrhal picture in upper respiratory tract, with odynophagia and runny nose.

One week after the bursitis she began with high fever and deterioration of the general state so she came to the emergency service of our hospital, where she admitted conscious, impressing of severe disease and fever of $38^{\circ} \mathrm{C}$. The analytical shows leukocytosis of $15.300 / \mu \mathrm{L}$ (82\% segmented, $12 \%$ lymphocytes, $6 \%$ monocytes, $0 \%$ eosinophils) and platelets of $169.000 / \mu \mathrm{L}$. In the physical examination the anterior cervical area was indurate but without superficial alterations of the skin's color or temperature rise.

Chest X-ray displays bilateral nodular images, and cervical, thoracic and abdominal tomography was performed, showing the presence of a phlegmonosum area at level of the inferior cervical wall, with invasion of the prelaryngeal muscles and posterior displacement of the thyroid and invasion of the right sternocleidomastoideus, in addition to the involvement of the proximal third of the major pectoralis and left deltoid. Chest tomography describes nodular lesions inside the pulmonary parenchyma, some of them peripherics and cavitated, suggestive of septic emboli and bilateral pleural effusion (Figure 1). Transesophageal echocardiography didn’t show the presence of valves vegetations.

Guideline broad-spectrum antibiotic treatment was started and Surgery Department, ruled out surgery because of the process was in phlegmonosum phase, without abscess at that time. In the next 72 hours, the patient worsened developing a septic shock with respiratory failure that required mechanical ventilation. A new CT was performed, showing progression of the previous collection affecting the cervical wall below the height of the cricoid cartilage, prelaryngeal muscle, sternocleidomastoideus muscle, left major pectoralis and left deltoid, left subclavian vein, subcutaneous tissues and mediastinum without signs of mediastinitis. The patient was transferred to operating room where debridement of the cervical area was made (Figure 2).

Ten days after the income a new chest CT was performed showing a septic thrombosis of the external jugular vein and the left subclavian vein, segmental artery of the upper left lobe, inferior lobar artery and posterobasal artery of the lower pulmonary lobe. Anticoagulant treatment with unfractionated heparin was began.

We established the diagnosis of Lemierre's syndrome due to clinical findings of infectious illness in the cervical area with thrombophlebitis of the venous vessels of the neck and the presence of septic embolic phenomena at several levels, including the lung, several muscle groups and left humeral arthritis.

Blood cultures were positive for Staphilococcus aureus methicillin sensitive. More advanced study of the isolated organism showed PCR positivity for Panton-Valentine leukocidin.

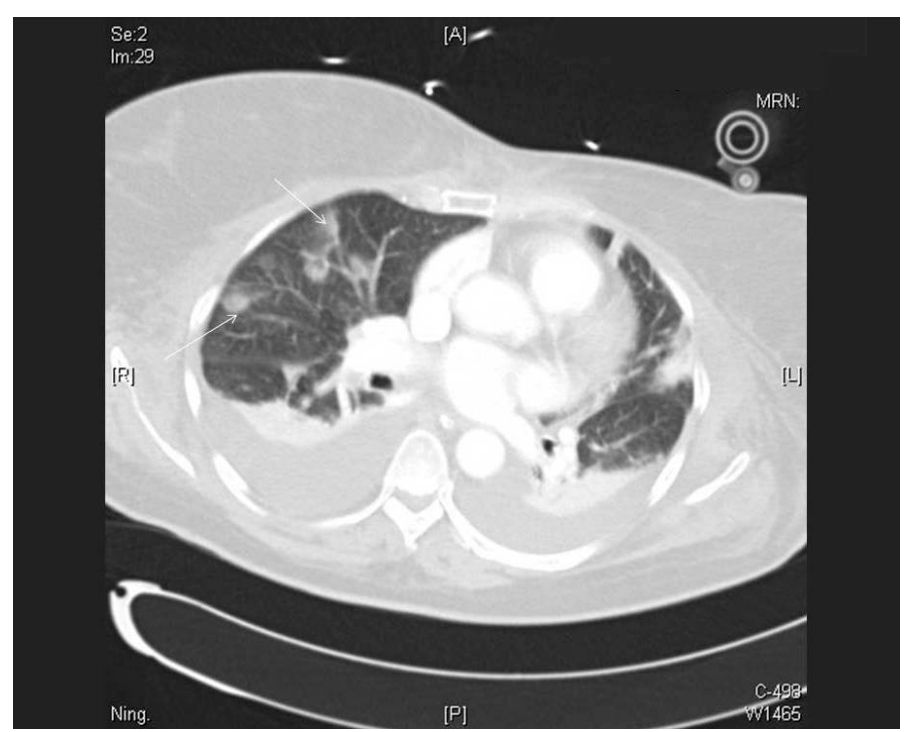

Figure 1. Chest tomography describes nodular lesions at the level of the pulmonary parenchyma, suggestive of septic emboli and bilateral pleural effusion. 


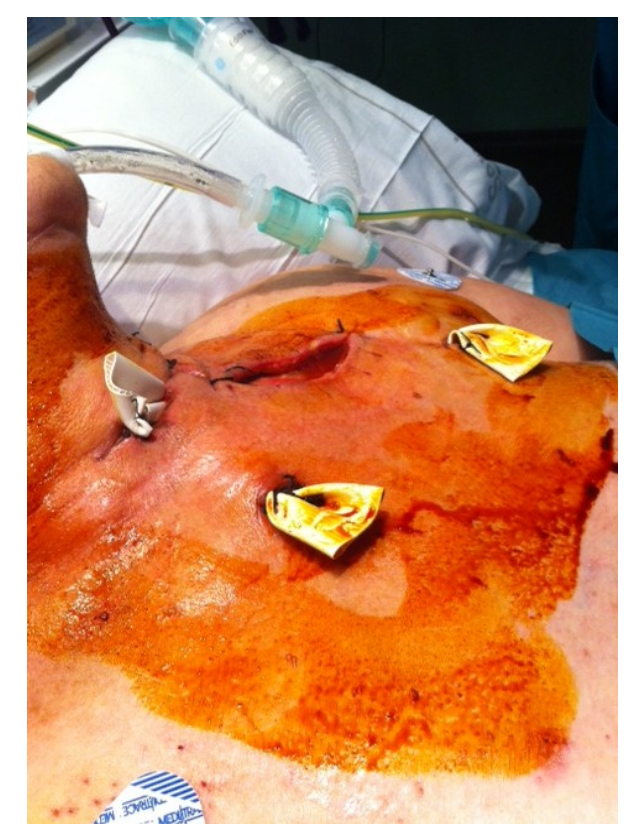

Figure 2. Debridement of the cervical area in the medial area of the left sternocleidomastoideus, lateral area of thyroid lobe, posterior yuguloesternal region, ipsilateral retroclavicular area and deltopectoral groove.

Twenty four days after the income the patient was transferred to internal medicine ward with endovenous antibiotic treatment, as well as local treatment of the wounds and systemic anticoagulation.

Finally, the patient was discharged from the hospital four moths later, with a good recovery. Actually she is on study by a possible development of plasmocitoma, after a monoclonal peak IgG Kappa was observed in the following controls.

\section{Discussion}

The most of cases of Lemierre's syndrome are described in previously healthy, adolescents and young adults, without immunological deficits or other risk factors for serious infections. The infection-producing organism is mainly the Prevotella necrophorum, anaerobic gram-negative bacteria which forms part of the common pharyngeal flora, as well as of the female genital area. There is also the possibility of polymicrobial infection, and in recent years some cases secondary to Staphylococcus aureus methicillin-resistant were described; in the case of methicillin sensitive bacteria collected cases are even much less frequent [3] [6].

The classic triad is the most common clinical picture at presentation. However, we need to know that pharyngeal symptoms may be often mild and even anodyne, giving the way within $1-2$ weeks to more evident signs in relation with the appearance of the thromboflebitis in the internal jugular vein or other veins of the neck and distant findings due to embolic phenomena [7]. More than $90 \%$ of the cases these emboli occur in lung, showing multiple bilateral nodules, some of them cavitated and bilateral.

Other frequent places of septic metastasis are the joints and bones, muscles, meninges, liver, spleen, etc. Atypical forms of presentation in which the first manifestation of the syndrome has been a monoarthritis have been described [8] [9].

Lemierre's syndrome diagnosis is clinical, supported by findings in the CT and Doppler ultrasound of the neck, that usually shows thrombosis in venous vessels and septic distant embolic phenomena.

In the case of our patient, the finding of Staphylococcus aureus methicillin sensitive is interpreted as a rare fact, because as discussed Staphylococcus are usually methicillin resistant. In addition, there is a positivity for leukocidin of the germ, which has been compared by various authors with its capacity for the invasion of soft tissue. We have not found any relationship with the previous infiltration of corticoids of the articulation, performed on an outpatient basis because it's likely that arthritis in this case was a earlier manifestation of the syn- 
drome, as it has also been published by other authors [10]. This fact supports the absence of inflammatory signs in the articulation both in physical exam at admission and in the CT.

\section{Conclusion}

Lemierre's syndrome must be always suspected in patients with febrile syndrome and evidence of septic embolisation, especially if it affects lungs or bones. The discovery of Staphylococcus aureus methicillin-sensitive is interpreted as a rare fact.

\section{Conflict of Interest}

The authors declare that they have no conflict of interest.

\section{References}

[1] Lemierre A. (1936) On Certain Septicaemia Due to Anaerobic Organisms. Lancet, 2, 701-703. http://dx.doi.org/10.1016/S0140-6736(00)57035-4

[2] Bang, Y.Y., Kim, J.-T., Chang, W.-H., Oh, T.Y. and Kong, J.-H. (2011) Lemierre Syndrome. The Korean Journal of Thoracic and Cardiovascular Surgery, 44, 437-439. http://dx.doi.org/10.5090/kjtcs.2011.44.6.437

[3] Fong, S.M. and Watson, M. (2002) Lemierre Syndrome Due to Non-Multiresistant Methicillin-Resistant Staphylococcus aureus. Journal of Paediatrics and Child Health, 38, 305-307. http://dx.doi.org/10.1046/j.1440-1754.2002.00784.x

[4] Lina, G., Piémont, Y., Godail-Gamot, F., Bes, M., Peter, M., Gauduchon, V., et al. (1999) Involvement of Panton-Valentin Leukocidin-Producing Staphylococcus aureus in Primary Skin Infections and Pneumonia. Clinical Infectious Diseases, 29, 1128-1132. http://dx.doi.org/10.1086/313461

[5] Hoehn, S. and Dominguez, T. (2002) Lemierre’s Syndrome: An Unusual Cause of Sepsis and Abdominal Pain. Critical Care Medicine, 30, 1644-1647. http://dx.doi.org/10.1097/00003246-200207000-00040

[6] Puymirat, E., Biais, M., Camou, F., Lefévre, J., Guisset, O. and Gabinski, C. (2008) A Lemierre Syndrome Variant Caused by Staphylococcus aureus. American Journal of Emergency Medicine, 26, 380.e5-380.e7.

[7] Fernández, J.L., Carcelén, I., Gutiérrez, J.M., Dones, J.J., Lea, M.C. and Navarro, J. (1999) Síndrome de Lemierre. Descripción de dos casos y revision de la literature. Seminario Médico, 51, 31-36.

[8] van Wissen, M., Gerdes, V., van Gorp, E., Brandjes, D. and Soesan, M. (2009) Unusual Presentation of Lemierre’s Síndrome: Two Cases and a Review. Blood Coagulation \& Fibrinolysis, 20, 466-469. http://dx.doi.org/10.1097/MBC.0b013e32832dc312

[9] Peters, E.J., van Helden, A.W. and Postma, B. (2011) A 25-Year-Old Male with Oligoarthritis as the First Sign of Lemierre's Syndrome. Infection, 39, 87-89. http://dx.doi.org/10.1007/s15010-010-0071-7

[10] Nisar, M.K., Kuttikat, A.V., Ramabhadran, B. and Fishman, D. (2013) Lemierre’s Syndrome: A Rare Cause of Septic Polyarthritis. Rheumatology International, 33, 817-8188. http://dx.doi.org/10.1007/s00296-011-2290-3 